\title{
Genome Sequence and Adaptation Analysis of the Human and Rice Pathogenic Strain Burkholderia glumae AU6208
}

\author{
Zhouqi Cui ${ }^{1,2,+}$, Sai Wang ${ }^{1,+}$, Kaleem Ullah Kakar ${ }^{2}$, Guanglin Xie ${ }^{3}$, Bin Li ${ }^{3} \mathbb{D}$, Gongyou Chen ${ }^{1} \mathbb{D}$ \\ and Bo Zhu $1, * \mathbb{D}$ \\ 1 Key Laboratory of Urban Agriculture by Ministry of Agriculture of China, School of Agriculture and Biology, \\ Shanghai Jiao Tong University, Shanghai 200240, China; zhouqicui@gmail.com (Z.C.); \\ wangsai@sjtu.edu.cn (S.W.); gyouchen@sjtu.edu.cn (G.C.) \\ 2 Department of Plant Pathology \& Ecology, the Connecticut Agricultural Experiment Station, \\ New Haven, CT 06511, USA; kakar1002@126.com \\ 3 State Key Laboratory of Rice Biology, Institute of Biotechnology, Zhejiang University, \\ Hangzhou 310027, China; glxie@zju.edu.cn (G.X.); libin0571@zju.edu.cn (B.L.) \\ * Correspondence: bzhu1981@sjtu.edu.cn \\ + These authors contributed equally.
}

check for updates

Citation: Cui, Z.; Wang, S.; Kakar, K.U.; Xie, G.; Li, B.; Chen, G.; Zhu, B. Genome Sequence and Adaptation Analysis of the Human and Rice Pathogenic Strain Burkholderia glumae AU6208. Pathogens 2021, 10, 87. https://doi.org/10.3390/pathogens 10020087

Academic Editor: Jong Hyun Ham Received: 1 December 2020

Accepted: 14 January 2021

Published: 20 January 202

Publisher's Note: MDPI stays neutral with regard to jurisdictional claims in published maps and institutional affiliations.

Copyright: (C) 2021 by the authors. Licensee MDPI, Basel, Switzerland. This article is an open access article distributed under the terms and conditions of the Creative Commons Attribution (CC BY) license (https:/ / creativecommons.org/licenses/by/ $4.0 /)$.

\begin{abstract}
Burkholderia glumae causes rice (Oryza sativa) bacterial panicle blight, which is an increasingly economically important disease worldwide. As the first B. glumae strain isolated from patients with chronic infections, AU6208 has been reported as an opportunistic clinic pathogen. However, our understanding of the molecular mechanism underlying human pathogenesis by B. glumae remains rudimentary. In this study, we report the complete genome sequence of the human-isolated B. glumae strain AU6208 and compare this to the genome of the rice-pathogenic B. glumae type strain LMG $2196^{\mathrm{T}}$. Analysis of the average nucleotide identity demonstrated $99.4 \%$ similarity between the human- and plant-pathogenic strains. However, the phenotypic results from this study suggest a history of niche adaptation and divergence. In particular, we found 44 genes were predicted to be horizontally transferred into AU6208, and most of these genes were upregulated in conditions that mimic clinical conditions. In these, the gene pair sbn $\mathrm{AB}$ encodes key enzymes in antibiotic biosynthesis. These results suggest that horizontal gene transfer in AU6208 may be responsible for selective advantages in its pathogenicity in humans. Our analysis of the AU6208 genome and comparison with that of LMG $2196^{\mathrm{T}}$ reveal the evolutionary signatures of B. glumae in the process of switching niches from plants to humans.
\end{abstract}

Keywords: Burkholderia glumae; bacterial panicle blight; chronic granulomatous; comparative analysis; horizontal gene transfer

\section{Introduction}

Burkholderia glumae is a Gram-negative plant pathogen that causes bacterial panicle blight (BPB) in rice (Oryza sativa) and wilting in a wide range of economically important vegetables such as pepper (Capsicum sp.), eggplant (Solanum melongena), and tomato (Solanum lycopersicum) [1,2]. To date, BPB has been reported in more than 21 countries throughout South and Central America, Africa, and Asia [3-8], causing costly damage (up to $75 \%$ yield reduction) to the rice industry [1].

To date, many rice-pathogenic B. glumae strains with different virulence levels have been identified in different countries [9]. Genome comparisons revealed weak variation in virulence-related genes between the strain BGR1 and the high-virulence strain 336gr-1 [1,10]. Later, it was proposed that the varied strains and broad host ranges of B. glumae may have been generated by the rapid rearrangement, inversion, or deletion of virulence-related genes [11]. Although comparative omics studies of B. glumae will provide evolutionary clues for exploring the unknown host-bacteria interactions, as well as the overall infection 
process, we lack comprehensive studies on the human-pathogenic B. glumae strain AU6208, which was isolated from patients with chronic granulomatous disease [12].

To understand the differences between B. glumae strains from different host niches, we generated and analyzed the complete genome sequence of the human-pathogenic strain AU6208. Interestingly, AU6208 was reported to be more virulent on rice than the rice-pathogenic strain BGR1 [13]. This result suggested that this human-pathogenic strain may have strong niche adaptation. Therefore, we investigated several interesting features pertaining to its virulence, evolution, and response to selective pressure by comparing AU6208 to the rice-pathogenic strain LMG $2196^{\mathrm{T}}$. Our results can help to determine the evolutionary changes that enable B. glumae adaptation for growth on different hosts.

\section{Results and Discussion}

\subsection{The Genetic Relationship between AU6208 and LMG $2196^{T}$}

To better understand the unique features of the human-pathogenic strain AU6208, we first sequenced its entire genome and analyzed general features of the full-length sequenced genome and assembly information (Table 1 and Figure 1). Based on PacbioIllumina hybrid sequencing, a total of 78,783 (14 Kb average read length) and 4,779,545 (2X150 bp pair-end) high-quality filtered reads were obtained from Pacbio and Illumina, respectively. The size of the B. glumae AU6208 whole genome is $6.06 \mathrm{Mbp}$ and the genome contains 5008 predicted coding sequences (CDSs), which are located on two chromosome DNA and one plasmid. Strikingly, the average nucleotide identity (ANI) between AU6208 and LMG $2196^{\mathrm{T}}$ was $99.45 \%$, suggesting an extremely high genetic similarity. The synteny analysis between the two strains also suggested the high synteny with some large-scale rearrangement (Figure 2). In total, 257 genes were found to be unique in AU6208 compared to LMG $2196^{\mathrm{T}}$ (Table S1). Most of these genes are annotated as hypothetical protein. Notably, the whole genome of B. glumae AU6208 contained 147 and 4 genes related to virulence and antibiotic resistance, respectively (Tables S2 and S3). Interestingly, the number of virulence- and antibiotic-resistance-related genes in LMG $2196^{\mathrm{T}}$ is virtually identical to that of AU6208, except that AU6208 contains two additional virulence-related genes encoding pmlR/bspR1 and BCAL3235 (Tables S2 and S3), which play important roles in capsule polysaccharide biosynthesis in Burkholderia cecocepacia [14].

Table 1. Genome statistics on Burkholderia glumae AU6208.

\begin{tabular}{cccc}
\hline Feature & Chromosome1 & Chromosome2 & Plasmid \\
\hline Contig length $(\mathrm{bp})$ & $3,629,551$ & $2,779,201$ & 122,067 \\
GC content * $\%)$ & 68.35 & 68.84 & 61.54 \\
Total genes & 3376 & 2262 & 122 \\
Protein-coding genes & 3139 & 2123 & 90 \\
tRNAS & 57 & 8 & 0 \\
rRNAS & 9 & 6 & 0 \\
ncRNAs & 4 & 0 & 0 \\
Pseudo genes & 167 & 125 & 32 \\
GenBank accession & CP047315 & CP047316 & CP047317 \\
\hline
\end{tabular}

* GC-content: the proportion of guanine-cytosine in genome. 

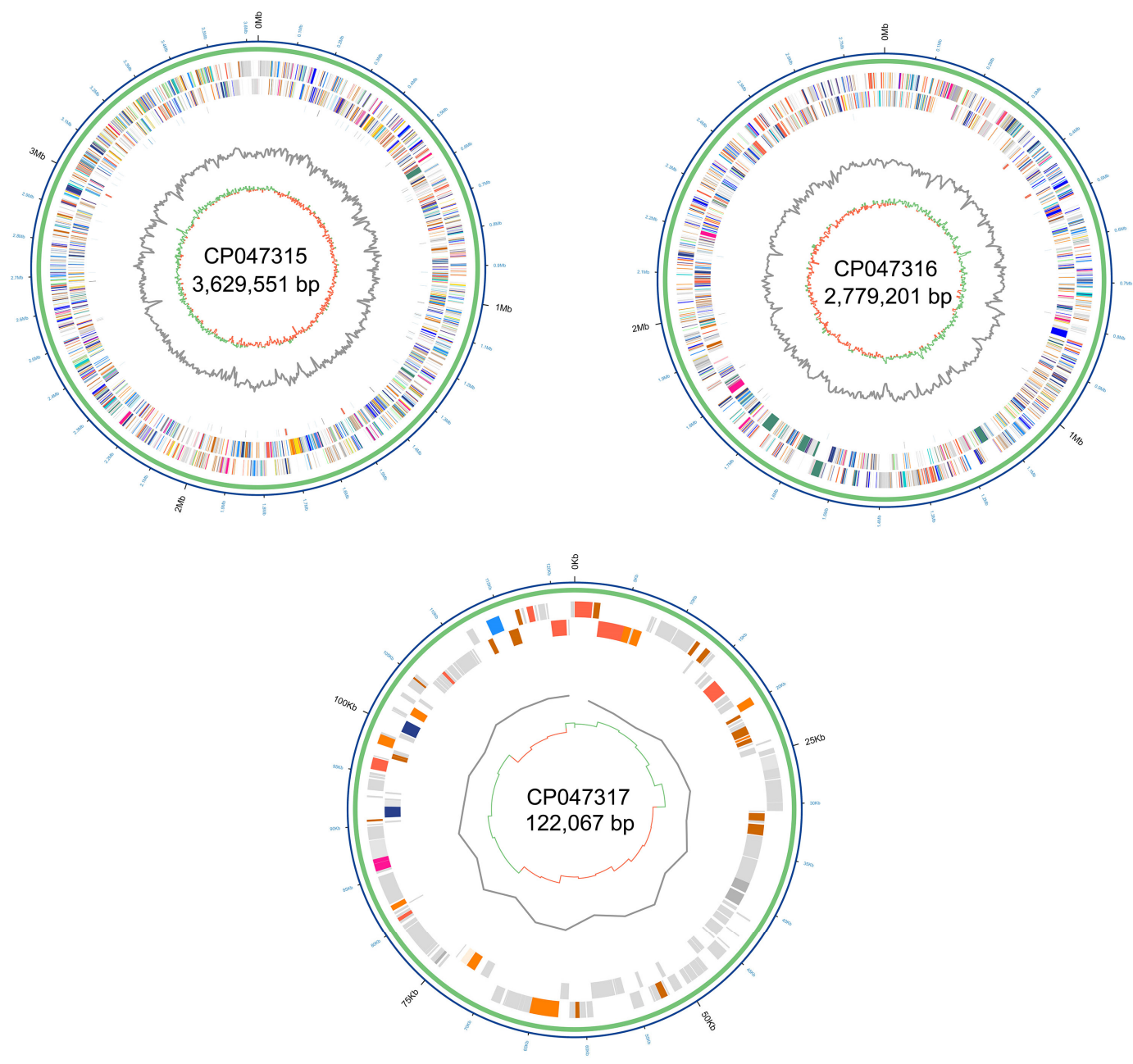

Figure 1. Circular representation of the complete genome of Burkholderia glumae strain AU6208. Rings from outside to the center: B. glumae AU6208 chromosome or plasmid, genes mapped against Clusters of Orthologous Groups (COG) database, RNA sequences, GC skew, and GC content.
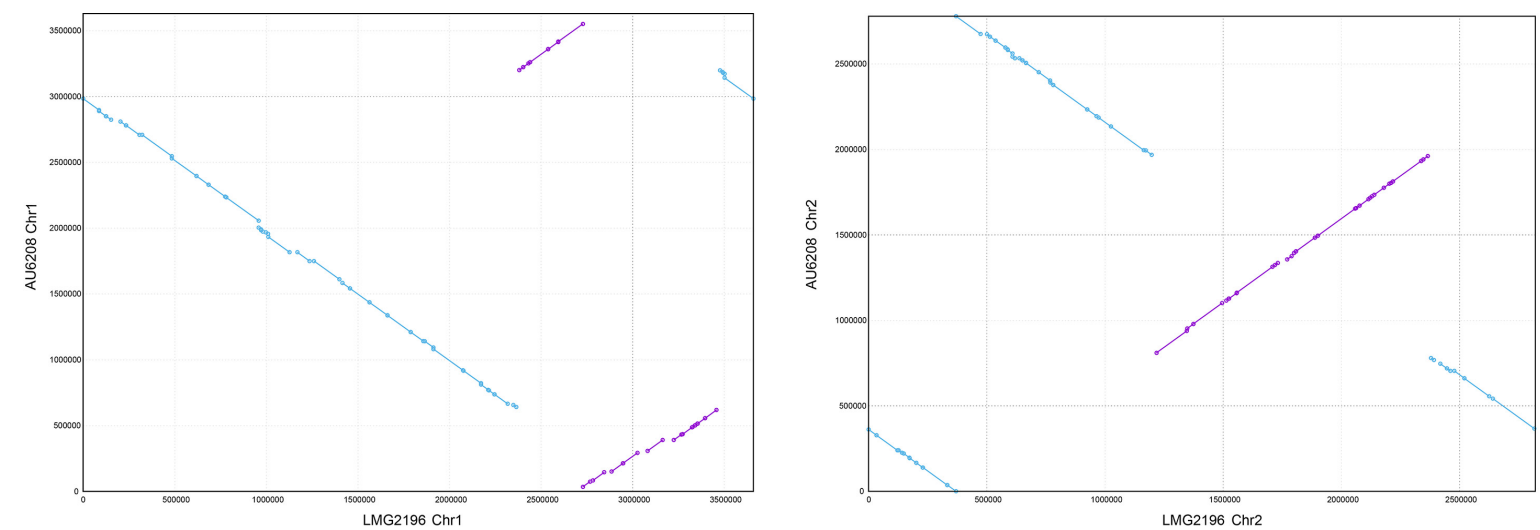

Figure 2. Genetic synteny visualized by MUMmer alignments. A comparison of the chromosomes of AU6208 and LMG $2196^{\mathrm{T}}$. The conserved gene synteny and some rearrangement between the chromosomes are observed. The purple dots represent the synteny genes between the two strains, while the blue dots represent the rearrangement genes. The lines connected by dots represent the high synteny regions (purple lines) or rearrangement (reverse arrangement) regions (blue lines). 


\subsection{AU6208 Showed Increased Biofilm Formation, EPS Secretion, and Virulence}

As mentioned above, $p m l R / b s p R 1$ and BCAL3235 may give AU6208 some advantages in biofilm formation and exopolysaccharide (EPS) secretion compared to LMG $2196^{\mathrm{T}}$. To confirm this hypothesis, we measured biofilm formation and EPS secretion in AU6208 ${ }^{\mathrm{WT}}$, AU6208 ${ }^{\triangle \mathrm{pmlR}}$ and the AU6208 ${ }^{\triangle \mathrm{BCAL} 3235}$ strains. The morphological appearance and thickness of the biofilm showed obvious differences after $48 \mathrm{~h}$ of adhesion at $30^{\circ} \mathrm{C}$ without agitation (Figure 3). In particular, the AU6208 strain formed a thicker biofilm compared to the AU6208 ${ }^{\triangle \mathrm{pmlR}}$ and AU6208 ${ }^{\triangle \mathrm{BCAL} 3235}$ strains. When quantified, WT (wild type) yielded readings at least four times as high as AU6208 ${ }^{\Delta \mathrm{pmlR}}$ and AU6208 ${ }^{\triangle \mathrm{BCAL} 3235}$ (Figure 3). The weight of EPS from AU6208 ${ }^{\mathrm{WT}}$ was at least twice as heavy as that from AU6208 ${ }^{\Delta \mathrm{pmlR}}$ and AU6208 ${ }^{\triangle \mathrm{BCAL} 3235}$ (Figure 3). The quantitative data confirmed that AU6208 exhibited a significantly $(p<0.001)$ higher biofilm-forming capability and EPS secretion compared to AU6208 ${ }^{\triangle \mathrm{pmlR}}$ and AU6208 ${ }^{\triangle \mathrm{BCAL} 3235}$. The above results strongly suggest that the $\mathrm{pmlR}$ and BCAL3235 gene in AU6208 contributes to increased biofilm formation and EPS secretion. In the virulence test in rice, we found that AU6208 ${ }^{\Delta \mathrm{pmlR}}$ and AU6208 ${ }^{\triangle \mathrm{BCAL} 3235}$ showed slightly decreased virulence compared to the WT (Figure 3). The complement strain showed a similar result compared to the WT (Figure 3).
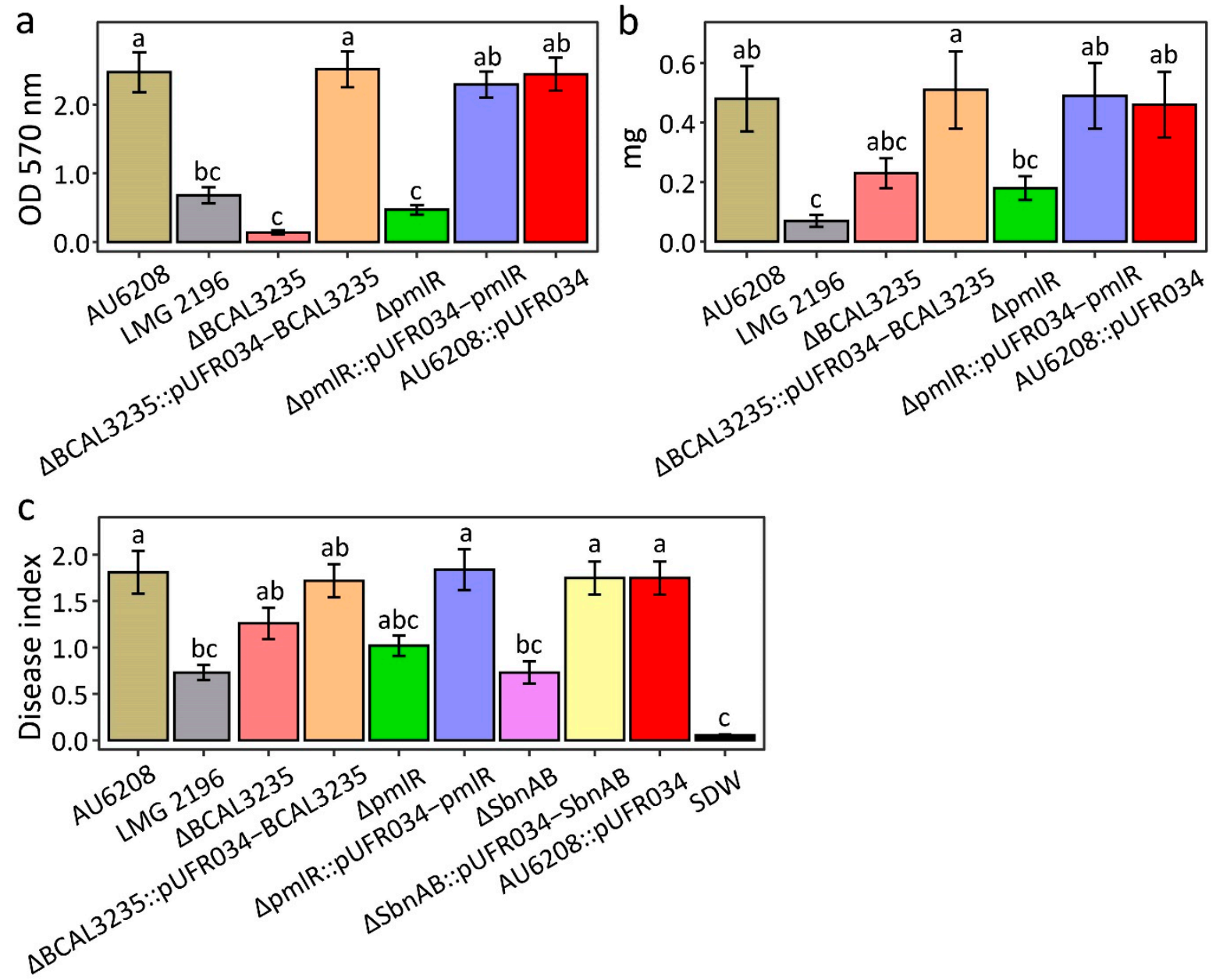

Figure 3. Biofilm formation, exopolysaccharide (EPS) production, and pathogenicity of B. glumae strains AU6208, LMG $2196^{\mathrm{T}}, \mathrm{AU} 6208^{\triangle \mathrm{BCAL3235}}, \mathrm{AU} 6208^{\triangle \mathrm{SbnAB}}, \mathrm{AU} 6208^{\Delta \mathrm{pmlR}}$, AU6208- pUFR034 empty vector control and their complementary strains. (a) Biofilm formation after a $48 \mathrm{~h}$ incubation; (b) EPS quantification after a $24 \mathrm{~h}$ incubation; (c) disease index in rice. All these experiments were repeated three times with four replicates. SDW: distilled water. Different letters denote statistical significance ( $p<0.05$, identified by analysis of variance comparisons of means, employing a posthoc Tukey-Cramer test for multiple comparisons). 
Interestingly, $p m l R / b s p R 1$ is a LuxR family transcriptional regulator, which may be involved in quorum sensing (QS). Devescivi et al. (2007) characterized the important role of QS in the strong rice virulence of B. glumae AU6208. They found that, compared with B. glumae LMG 2196 ${ }^{\mathrm{T}}$, the active TofR (a LuxR family regulator) present in AU6208 is the reason to cause strong disease symptom in rice [13]. In this study, since we achieved the whole sequences of both strains, the result of comparative genomic analysis presented that the $p m l R / b s p R 1$ is unique for AU6208 but not in LMG 2196 ${ }^{\mathrm{T}}$. Since the $p m l R / b s p R 1$ has been demonstrated as the key regulator responsible for the expression of LuxR and virulence of Burkholderia pseudomallei [15], it is reasonable to suggest that $p m l R / b s p R 1$ regulated LuxR system plays a key role in virulence of strain AU6208, which in terms that the weak virulence of LMG $2196^{\mathrm{T}}$ may be because of the incomplete LuxR system (QS). Moreover, since the QS is responsible for the biofilm formation, the data in this study also suggested that the presence of active $p m l R / b s p R 1$ in $B$. glumae is critical for the formation of biofilm matrix (Figure 3). This is in agreement with reports for many human pathogens in Burkholderia family. For instance, it is well demonstrated that pmlR is critical for full virulence of Burkholderia pseudomallei, the causative agent of melioidosis [15]. In this respect, the presence of the QS system appears to be an indicator of the virulence capacity of Burkholderia family, at least of B. glumae.

Besides $p m l R / b s p R 1$, BCAL3235 is another unique gene present in AU6208 compared to LMG 2196T. BCAL3235 encoded UDP-galactopyranose mutase (UGM) is a unique flavin-dependent enzyme, which converts UDP-galactopyranose (UDP-Galp) to UDPgalactofuranose (UDP-Galf), the major component of cell surface glycoproteins and glycolipids [16]. UGM presents in a variety of pathogenic fungi and bacteria, such as Aspergillus, E. coli, Klebsiella, and Mycobacteria [17]. The UGM has been identified in Burkholderia cepacian complex [18], which is a common causal agent of human chronic granulomatous disease. Thus, the finding of BCAL3235 in B. glumae strain AU6208 but not rice pathogen LMG $2196^{\mathrm{T}}$ strongly suggested that the gene may be achieved from bacteria survived in similar niche for adaption.

\subsection{Horizontal Gene Transfer May Contribute to Niche Adaptation in AU6208}

To further understand the niche adaptation in B. glumae AU6208, we compared the whole-genome expressed proteins of AU6208 under the human mimic [19] and in planta mimic [20] conditions using 2D SDS-PAGE, and the results shown are a representative expression from duplicate experiments (Figure S1). Most of the genes were expressed in both conditions. Notably, 30 proteins were expressed only in one condition (Figure S1). These differentially expressed proteins were digested and further examined by LC-MS/MS and the transcriptomic levels of the corresponding genes were determined by using qRTPCR. Twenty-two genes showed a dramatic increase in expression under human mimic condition compared to planta mimic condition (Table 2). Of which, two virulence genes $(s b n A$ and $\operatorname{sbn} B)$ were uniquely presented in AU6208. These data suggest that these genes may be responsible for bacterial survival and virulence in human host. To investigate whether these genes are achieved from microorganisms for niche adaption, we conducted a comprehensive horizontal gene transfer (HGT) analysis (Method 3.6) and total 44 genes were predicted to be horizontally transferred to AU6208 from other organisms (Table S4). Furthermore, 12 of the 22 (marked yellow at Table 2) significantly expressed genes (54.5\%) belonged to the horizontally transferred genes. Although the transmission of B. glumae from rice condition to human condition is still unclear, these data indicated that horizontal gene transfer plays some role in the niche adaption of B. glumae strain AU6208. 
Table 2. List of qPCR results from 30 proteins detected by 2D-MS/MS.

\begin{tabular}{|c|c|c|c|}
\hline Number & Gene & $\begin{array}{l}\text { Protein Name or Predicted Function/Bacterial } \\
\text { Species }\end{array}$ & Fold Change * \\
\hline A16 & BCAL3235 & putative UDP-galactopyranose mutase & 36.76 \\
\hline A52 & $\mathrm{pmlR} / \mathrm{bspR} 1$ & LuxR family transcriptional regulator & 78.79 \\
\hline A118 & SbnA & 2,3-diaminopropionate biosynthesis protein & 2048.00 \\
\hline B01 & SbnB & 2,3-diaminopropionate biosynthesis protein & 39.40 \\
\hline B05 & PqqE & pyrroloquinoline quinone biosynthesis protein & 2521.38 \\
\hline B19 & PqqD & pyrroloquinoline quinone biosynthesis peptide chaperone & 256.00 \\
\hline B20 & PqqC & pyrroloquinoline-quinone synthase & 1024.00 \\
\hline B21 & PqqB & pyrroloquinoline quinone biosynthesis protein & 3104.19 \\
\hline C 38 & Y5A_023325 & (2Fe-2S)-binding protein & 157.59 \\
\hline E09 & Y5A_015930 & LysR family transcriptional regulator & 238.86 \\
\hline E21 & Y5A_026480 & hypothetical protein & 5404.70 \\
\hline E28 & Y5A_005305 & aldo/keto reductase & 8.57 \\
\hline E31 & Y5A_024170 & benzaldehyde dehydrogenase & 168.90 \\
\hline E46 & Y5A_018250 & class I SAM-dependent DNA methyltransferase & 776.05 \\
\hline F07 & flmH & 3-oxoacyl-ACP reductase & 128.00 \\
\hline F10 & hemB & Porphobilinogen synthase & 2048.00 \\
\hline F23 & sodB & superoxide dismutase & 84.45 \\
\hline G30 & alcE & putative iron-sulfur protein & 1024.00 \\
\hline G95 & gmd & GDP-mannose 4,6-dehydratase & 4389.98 \\
\hline G122 & $\mathrm{rmlC}$ & dTDP-4-dehydrorhamnose 3,5-epimerase & $10,085.54$ \\
\hline H11 & katG & catalase/peroxidase HPI & 25.99 \\
\hline $\mathrm{H} 63$ & $\operatorname{alg} U$ & RNA polymerase sigma-H factor & 207.94 \\
\hline A139 & Y5A_006000 & Lysine decarboxylase & 2.14 \\
\hline B08 & msrB & methionine-R-sulfoxide reductase & 1.52 \\
\hline $\mathrm{B} 27$ & Y5A_011315 & hypothetical protein & 1.41 \\
\hline D06 & PhnA & Alkylphosphonate utilization operon protein & 1.52 \\
\hline E13 & Y5A_006405 & NADH dehydrogenase subunit C & 0.62 \\
\hline E26 & Y5A_011635 & aldo/keto reductase family oxidoreductase & 0.66 \\
\hline F01 & Y5A_002530 & ferritin, Dps family protein & 1.52 \\
\hline G32 & Y5A_007875 & Ankyrin repeat-containing protein & 1.32 \\
\hline
\end{tabular}

* The fold-change data are the expression level under human mimic medium compared to that under planta mimic medium.

Interestingly, we found that a gene pair, $\operatorname{sbn} A B$, which is involved in staphyloferrin $\mathrm{B}$ biosynthesis, is among the 44 horizontally transferred genes [21]. Phylogenetic analysis of both genes strongly suggests their Streptomyces origin with strong bootstrap support (Figure 4). It has been reported that staphyloferrin B is a hydrophilic siderophore, which plays an important role in pathogenicity in both human and plant pathogens [22,23]. Pathogenicity results confirmed that the AU6208 ${ }^{\triangle \mathrm{SbnAB}}$ mutant, which lacks SbnAB, induced no obvious symptoms on the rice plants (Figure 3). The complement strain showed a similar result compared to the WT (Figure 3). This result may be partially explained by the requirement of siderophore biosynthesis in bacteria for plant colonization [24]. 
a

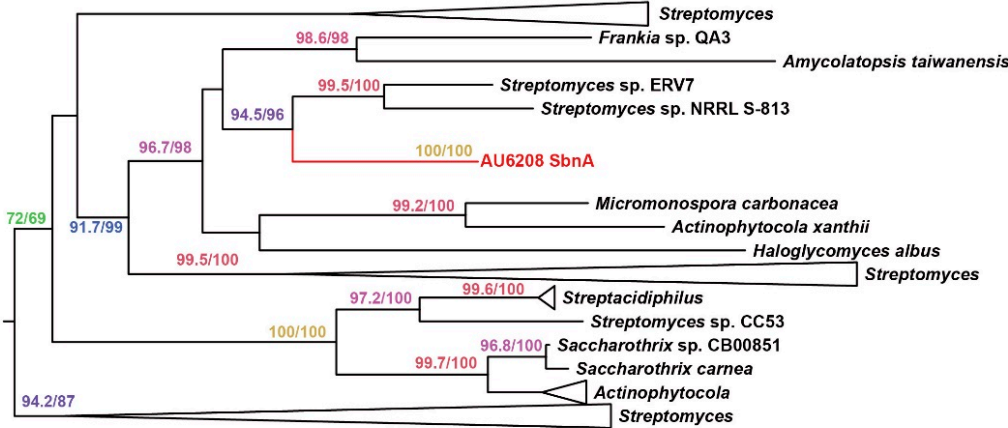

0.2

b

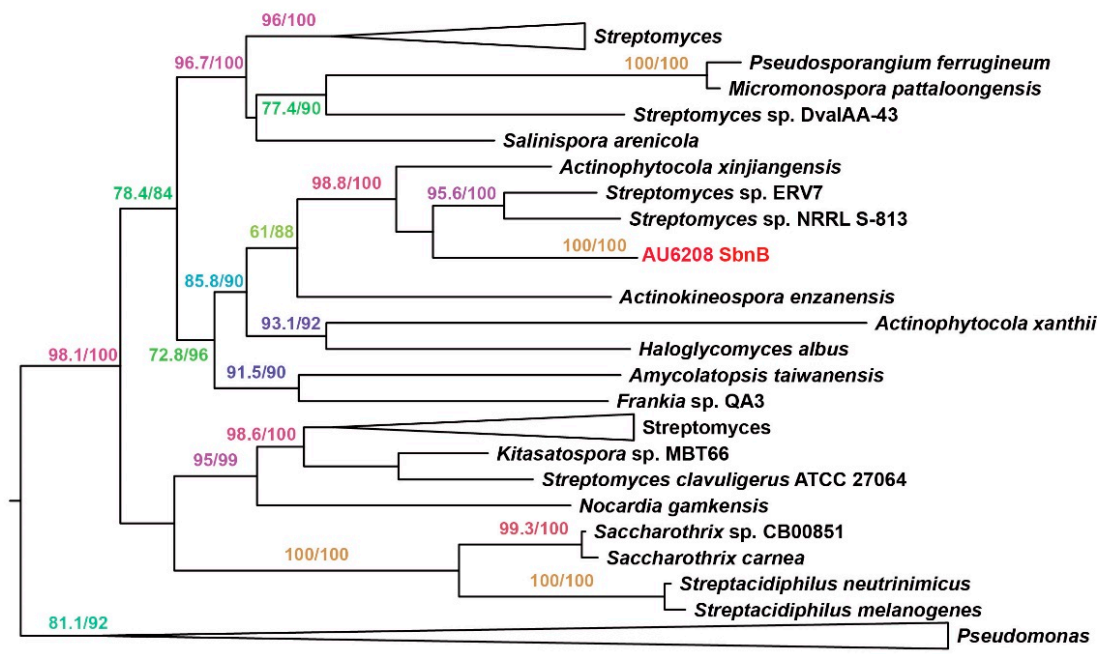

Pseudomonas

Figure 4. Phylogeny of (a) SbnA and (b) SbnB. The phylogenetic tree was calculated using the maximum likelihood program PhyML and Bayesian program MrBayes (detailed parameters are described in the main text). Only the values in ML $\geq 70 \%$ and Bayesian posterior probability $\geq 65 \%$ are shown. For key nodes, the actual support values are shown in the order ML bootstraps/Bayesian posterior probability. Bar, 0.1 substitution per site.

Overall in this study, we reported the complete genome of the human-pathogenic $B$. glumae strain AU6208 and compared it with that of the plant-pathogenic strain LMG $2196^{\mathrm{T}}$. This study is the first to report the whole genome of a human-pathogenic B. glumae strain, AU6208. Our comparative genomic analysis revealed increased diversity in this pathogen induced by different niche survival needs. We explored the differences in molecular mechanisms of virulence and the difference in the interaction of the human-pathogenic B. glumae strain AU6208 and rice-pathogenic B. glumae strains with rice. Our results provide insight into the different ecological niches of B. glumae strains resulting from differences in virulence and environmental adaptation, as well as their unique interactions with the host during pathogenesis.

\section{Materials and Methods}

\subsection{Bacterial Strains, Plasmids, and Growth Conditions}

B. glumae strains and plasmids used in this study are listed in Table 3. All strains were stored at $-80{ }^{\circ} \mathrm{C}$ in $20 \%$ glycerol and grown in nutrient broth (NB) medium ( $1 \%$ peptone, $0.3 \%$ yeast extract, and $0.5 \% \mathrm{NaCl}, \mathrm{pH} 7.5$ ) at $30^{\circ} \mathrm{C}$. Luria-Bertani (LB) agar without sucrose and LB agar containing $10 \%(w / v)$ sucrose were used for deletion mutagenesis. Antibiotics 
were added at the following concentrations when required: $50 \mu \mathrm{g} / \mathrm{mL}$ kanamycin $(\mathrm{Km})$, $100 \mu \mathrm{g} / \mathrm{mL}$ ampicillin (Amp) and $10 \mu \mathrm{g} / \mathrm{mL}$ neomycin (Nm).

Table 3. Strains and plasmids used in this study.

\begin{tabular}{|c|c|c|}
\hline Strain or Plasmid & Relevant Characteristics $^{a}$ & Source or Reference \\
\hline \multicolumn{3}{|l|}{ Burkholderia Glumae } \\
\hline AU6208 & $\begin{array}{l}\text { Human pathogen isolated from surgical } \\
\text { specimens from lung lesions in an } \\
\text { 8-month-old boy }\end{array}$ & Weinberg et al., 2007 \\
\hline LMG $2196^{\mathrm{T}}$ & Isolated from Oryza sativa, grain & Shannon Johnson, 1967 \\
\hline AU6208 $\triangle$ BCAL3235 & $\begin{array}{l}\text { AU6208 deletion mutation defective in } \\
\text { BCAL3235 }\end{array}$ & This study \\
\hline AU6208 $8^{\triangle S b n A B}$ & $\begin{array}{l}\text { AU6208 deletion mutation defective in } \\
\text { SbnAB }\end{array}$ & This study \\
\hline AU6208 $8^{\Delta \mathrm{pmlR}}$ & $\begin{array}{l}\text { AU6208 deletion mutation defective in } \\
\text { pmlR }\end{array}$ & This study \\
\hline \multicolumn{3}{|l|}{ Escherichia coli } \\
\hline $\mathrm{DH} 5 \alpha$ & $\begin{array}{c}\mathrm{F}^{-} \text {Ф80d lacZ } \Delta \mathrm{M} 15 \Delta(\operatorname{lac} Z Y A-\arg F) \mathrm{U} 169 \\
\left.\text { recA1 endA1, hsdR17( } \mathrm{r}_{\mathrm{k}}^{-}, \mathrm{m}_{\mathrm{k}}^{+}\right) \text {phoA } \\
\text { supE } 44 \lambda^{-} \text {thi-1 gyrA96 relA1 }\end{array}$ & This study \\
\hline S17-1( $\lambda$ pir $)$ & $\begin{array}{l}\lambda \text { Lysogenic S17-1 derivative producing } \pi \\
\text { protein for replication of plasmids } \\
\text { carrying oriR6K; } \\
\text { recAprohsdRRP4-2-Tc::Mu-Km::Tn7 } \lambda^{-} \text {pir }\end{array}$ & Simon et al., 1983 \\
\hline & \multicolumn{2}{|l|}{ 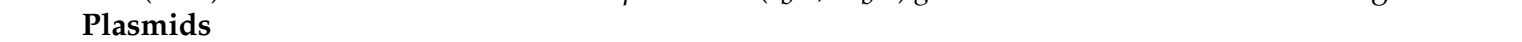 } \\
\hline pGEM-T & $A m p^{R} ;$ cloning vector & Promega \\
\hline pUFR034 & $\begin{array}{c}\text { IncW Nm }{ }^{\mathrm{r}} \mathrm{Mob}^{+} m o b(\mathrm{P}) \text { lacZ alpha } \\
\operatorname{Par}^{+} \cos \end{array}$ & DeFeyter et al., 1990 \\
\hline pKMS1 & $\begin{array}{l}\mathrm{Km}^{\mathrm{R}} \text {; R6K-based suicide vector; requires } \\
\text { the pir-encoded } \pi \text { protein for replication }\end{array}$ & Zou et al., 2011 \\
\hline AU6208- pUFR034 & Empty vector control & This study \\
\hline pKMS1- BCAL3235 & $\begin{array}{l}\mathrm{Km}^{\mathrm{R}} \text {; used to create knockout mutant of } \\
\text { AU6208 }\end{array}$ & This study \\
\hline pUFR034- BCAL3235 & $\begin{array}{c}\mathrm{Km}^{\mathrm{R}} \text {; used to create complement of } \\
\text { AU6208 }\end{array}$ & This study \\
\hline pKMS1-SbnAB & $\begin{array}{c}\mathrm{Km}^{\mathrm{R}} \text {; used to create knockout mutant of } \\
\text { AU6208 }\end{array}$ & This study \\
\hline pUFR034- SbnAB & $\begin{array}{c}\mathrm{Km}^{\mathrm{R}} \text {; used to create complement of } \\
\text { AU6208 }\end{array}$ & This study \\
\hline pKMS1-pmlR & $\begin{array}{c}\mathrm{Km}^{\mathrm{R}} \text {; used to create knockout mutant of } \\
\text { AU6208 }\end{array}$ & This study \\
\hline pUFR034- pmlR & $\begin{array}{c}\mathrm{Km}^{\mathrm{R}} \text {; used to create complement of } \\
\text { AU6208 }\end{array}$ & This study \\
\hline
\end{tabular}

${ }^{\mathrm{a}} \mathrm{Km}^{\mathrm{R}}$ and $\mathrm{Amp}^{\mathrm{R}}$ indicate kanamycin and ampicillin resistant.

\subsection{DNA Extraction, Genome Sequencing, and Genomic Analysis}

Bacterial genomic DNA was extracted using TIANamp Bacteria DNA kits (Tiangen Biotech, Beijing, China). Whole-genome DNA sequencing of B. glumae AU6208 was conducted using the Pacific Biosciences (PacBio) RSII Single Molecule Real Time (SMRT) system and Illumina with the NEBNext Ultra DNA Library Prep Kit (New England Biolabs, MA, USA). The combination of PacBio and Illumina sequence shotgun data was assembled with the SMRT analysis packages (v2.1) using hierarchical genome assembly [25]. Low-quality sequences were filtered by Sickle (v1.33) with Q30 (https:/ / github.com/najoshi/sickle). Protein-coding regions, tRNAs, and rRNAs were predicted using rapid annotation subsystem technology [26]. Hits were then analyzed for signal peptide characteristics using 
SignalP [27]. Transmembrane domains and functional protein domains were analyzed using tied-mixture hidden Markov modeling and InterProScan, respectively [28,29]. The secondary metabolite clusters, antibiotic resistance clusters and toxins, and virulence factors were predicted by comparing with DoBISCUIT, CARD, and VFDB databases, respectively [30-32]. The category of functional proteins was further annotated by Clusters of Orthologous Groups (COG) and Gene Ontology databases [33]. Genome comparison between AU6208 and LMG $2196^{\mathrm{T}}$ was conducted using average nucleotide identity (ANI) and alignment fraction (AF), which were calculated by an ANIcalculator [34]. Synteny of genome structure between AU6208 and LMG $2196^{\mathrm{T}}$ was performed by Mummer 3.0 with default parameters [35].

\subsection{Construction of Deletion Mutants and Complementation}

To investigate the role of genes of interest in AU6208, we constructed deletion mutants in AU6208 using homologous recombination. Briefly, two fragments flanking the left and right borders of corresponding genes were amplified from the wild-type genomic DNA with the primer pairs listed in Table S4. The amplified fragments were cloned into pGEM-T (Promega), confirmed by sequence analysis, and then digested and subcloned into vector pKMS1 [36] at BamHI and PstI (or SalI) sites. The resulting recombinant plasmids were introduced into AU6208 by electroporation, and transformants were plated on NA plates supplemented with kanamycin. Colonies resulting from a single homologous crossover (integration of the deletion construct at either the left or right border of the target gene) were then transferred to NBN broth, grown for $12 \mathrm{~h}$ at $28{ }^{\circ} \mathrm{C}$, and then plated on NAS plates for sucrose-positive deletion mutant selection. Sucrose-resistant colonies were visible within 3 to 4 days and then transferred to NA plates and NA plus kanamycin plates. Kanamycinsensitive colonies could be mutants containing a second homologous crossover, which was further confirmed by PCR amplification.

In order to complement the deletion mutants, the full-length of corresponding genes including native promotors were amplified using primer pairs listed in Table S5. After confirmation by sequence analysis, the amplified DNA fragments were cloned into pUFR034 [37] at the BamHI and SalI sites to create the recombinant plasmids, the recombinant plasmids were transferred into corresponding mutants by electroporation, and transformants were screened on NA plates with neomycin. Colonies were visible within 3 to 4 days growing at $28^{\circ} \mathrm{C}$. A putative transformant was shown to contain plasmid by PCR analysis.

\subsection{Biofilm Formation and Exopolysaccharide (EPS) Secretion Assay}

Biofilm formation was determined using a previously described method [38]. In brief, bacterial cells grown overnight were inoculated 1:100 in fresh NB media in a 96-well microplate (Corning-Costar Corp., Corning, NY, USA). After static culture at $30{ }^{\circ} \mathrm{C}$ for $48 \mathrm{~h}$, cells were stained with $1 \%$ crystal violet $(\mathrm{CV})$ for $15 \mathrm{~min}$. The planktonic cells were removed by several rinses with $\mathrm{H}_{2} \mathrm{O}$. The $\mathrm{CV}$-stained bound cells were air-dried for $1 \mathrm{~h}$ and dissolved in $90 \%$ ethanol, and the optical density at $590 \mathrm{~nm}\left(\mathrm{OD}_{590}\right)$ of the solution was measured to quantify biofilm formation.

The extraction and quantitation of bacterial EPS were performed as described previously [39]. Briefly, overnight bacterial cultures were inoculated 1:100 in $100 \mathrm{~mL}$ fresh $\mathrm{NB}$ media to $\mathrm{OD}_{600}=1.0$. Cultures were centrifuged at $4{ }^{\circ} \mathrm{C}$, and $100 \mu \mathrm{l}$ of the supernatant was collected and filtered through $0.22-\mu \mathrm{m}$ Millipore filters to remove all bacterial cells. A mixture of one volume of supernatant with four volumes of Sevage's solution (4:1 chloroform:butanol) was incubated with shaking at $180 \mathrm{rpm}$ for $30 \mathrm{~min}$. Subsequently, the supernatants were collected by centrifuging and then mixed with three volumes of $95 \%$ ethanol and incubated at $4{ }^{\circ} \mathrm{C}$ for $24 \mathrm{~h}$ without shaking. The pellet was harvested, dried, and weighed after incubation. The experiments consisted of three biological replicates and were repeated at least three times. 


\subsection{Pathogenicity Assay}

In a greenhouse, rice plants (Oryza sativa cv. kitaake) were inoculated at the flowering stage with approximately $1 \times 10^{9} \mathrm{CFU} / \mathrm{mL}$ of $B$. glumae. Disease symptoms in the rice were evaluated on day 10 after inoculation. The disease index was determined as described previously [40]. In detail, the disease score was defined as $0=$ healthy panicle, $1=$ panicle 0 to $20 \%$ discolored, $2=$ panicle 20 to $40 \%$ discolored, $3=$ panicle 40 to $60 \%$ discolored, $4=$ panicle 60 to $80 \%$ discolored, and $5=$ panicle 80 to $100 \%$ discolored (disease index $=\sum$ (number of samples per score $\mathrm{X}$ score)/the total number of panicles). Pathogenicity assays were repeated three times with four replicates.

\subsection{Horizontal Gene Transfer (HGT) Analysis}

Screening for HGT was first performed by HGTfinder with default parameters [41]. Confirmation of HGT was performed by a combination of BLAST screening and large-scale phylogenetic trees. BLAST screening was performed based on our previous study [42]. In brief, candidate sequences in B. glumae were compared against sequences in the NCBI (National Center for Biotechnology Information) reference genome using BLASTp [43] followed by extracting the sequences with highest similarity for further study. We considered two genes orthologs when the E-value $<10^{-10}$ and when the alignment similarity was higher than $30 \%$ with more than $85 \%$ coverage [44]. These sequences were aligned using MAFFT [45], and the conserved region of each alignment was trimmed using TrimAI [46] with stringent settings. Maximum likelihood and Bayesian phylogenies were generated based on our previous study [42].

\subsection{Preparation of Bacterial Samples Isolated from Different Niches for 2-Dimensional Electrophoresis}

For the human mimic condition, overnight bacterial cultures of B. glumae AU6208 and LMG2196 from one single colony in NB broth were trans-cultured as 1:100 in $100 \mathrm{~mL}$ fresh SCFM2 (Human mimic medium) [19] and incubated with shaking at $200 \mathrm{rpm}$ at $30{ }^{\circ} \mathrm{C}$ until the $\mathrm{OD}_{600}$ reached 0.8 . Cells were then collected by centrifugation at $5000 \times g$ for $10 \mathrm{~min}$, washed with $0.5 \times$ phosphate-buffered saline (PBS) three times, and used for protein extraction. For the in planta mimic condition, we collected the bacterial samples using the previous method [20]. In brief, the rice leaves were collected and homogenized by liquid nitrogen with a mortar and pestle. The resultant was aliquoted to $1 \mathrm{~g}$ in tubes and stored at $-80^{\circ} \mathrm{C}$ before using. The $1 \mathrm{~g}$ of freezing rice leaf resultant was thaw on ice and added into $40 \mathrm{~mL}$ of nutrient broth to ready as the planta mimic medium. Single colony of B. glumae strains was inoculated into the medium and grew to the mid-exponential phase $\left(\mathrm{OD}_{600}=0.5\right)$. The bacterial pellets were harvested from $1.5 \mathrm{~mL}$ bacterial suspension by centrifugation at $5000 \times g$ for $20 \mathrm{~min}$, washed with $0.5 \times$ PBS three times, and used for protein extraction. Extraction of total proteins and 2-dimensional electrophoresis were performed as previously described [47]. The resulting protein profiles were analyzed with ImageMaster 2D platinum, version 5.0 (Amersham Biosciences, Uppsala, Sweden).

\subsection{Protein in-Gel Digestion and Liquid Chromatography-Tandem Mass Spectrometry (LC-MS/MS) Analysis}

The tryptic in-gel digestion protocol, optimized for a polyacrylamide gel of $1.5 \mathrm{~mm}$ thickness, was performed based on a previous method [48]. Briefly, protein spots were excised from the gel and put into the 96-well polypropylene ZipPlate Micro-SPE plate (Thermo). Then, the gel piece was rinsed for $40 \mathrm{~min}$ with $100 \mu \mathrm{L}$ of $25 \mathrm{mM}$ ammonium bicarbonate/acetonitrile $(95: 5, v / v)$ followed by two rinses with $100 \mu \mathrm{L}$ of $25 \mathrm{mM}$ ammonium bicarbonate/acetonitrile $(50: 50, v / v)$. The gel piece was then dehydrated for $12 \mathrm{~min}$ with $200 \mu \mathrm{L}$ of acetonitrile. Digestion was performed with $15 \mu \mathrm{L}$ of sequencing grade porcine trypsin $\left(10 \mathrm{ng} \mu \mathrm{L}^{-1}\right)$ at $37^{\circ} \mathrm{C}$ for $3 \mathrm{~h}$.

The peptides released from trypsin digestion for LC-MS/MS analysis were prepared in two biological replicates. LC was performed using a Dionex Ultimate 3000 nano-LC 
system following the method in our previous paper [49]. The MASCOT LC-MS/MS ion search algorithm (Matrix Sciences) was applied to evaluate the LC/MS spectra, and the sequence similarity of resulting peptides to the B. glumae AU6208 strain was compared to other Burkholderia species accessible on NCBI. To further identify the proteins, the crosscorrelation (X corr) scores of singly, doubly, and triply charged peptides were fixed greater than 1.8, 2.5, and 3.5, respectively [49]. Peptide sequences with the highest $X$ corr values were then identified.

\subsection{Quantitative Real-Time PCR}

Total RNAs were extracted from exponentially growing cells, using a RNeasy Mini spin columns Kit (Qiagen) and was treated with a unit of RNase-free DNase I (Qiagen), and cDNA synthesis was performed with a Moloney murine leukemia virus reverse transcriptase first-strand cDNA synthesis kit (QIAGEN). The cDNA was then used directly as the template for qRT-PCR using a SYBER Green master mix (Protech Technology Enterprise Co., Ltd.) on an ABI Prism 7000 sequence detection system (Applied Biosystems). Primers for quantitative real-time PCR (qRT-PCR) of the selected genes were designed by using Primer 3 [50] and gyrB was used as an internal control. Ct values were shown on Table S5.

\subsection{Statistical Analysis}

Statistically significant differences in the disease index, biofilm formation and EPS production were identified with a one-way ANOVA and Tukey-Kramer post-hoc test in the agricolae package in $R$.

\subsection{Availability of Data and Materials}

All data supporting the conclusions of this article are included in this article and its additional files. The complete genome sequences have been deposited at DDBJ/EMBL/GenBank and the bioproject ID is PRJNA595825.

Supplementary Materials: The following are available online at https://www.mdpi.com/2076-0 817/10/2/87/s1, Figure S1: 2-DE maps of total proteins from B. glumae strain AU6208 expressed under human mimic and in planta mimic conditions. The labeled spots are the typical results of specific expressed proteins., Table S1: Unique genes in AU6208 compared to LMG 2196 ${ }^{\mathrm{T}}$, Table S2: Antibiotic Resistance genes in AU6208 and LMG 2196, Table S3: Virulence genes in AU6208 and LMG 2196, Table S4: Horizontal gene transfer in AU6208, Table S5: List of qPCR results from 30 proteins detected by 2D-MS/MS.

Author Contributions: Z.C. conceived and led the project, prepared bacteria, DNA for sequencing and phenotypic experiments; S.W. assembled the genome, made predictions, annotated genes and performed other bioinformatics analyses; K.U.K., G.X. and B.L. contributed to the project; B.L. acted as a scientific consultant; B.Z. wrote the manuscript. All authors prepared tables and figures, edited and approved the final manuscript. All authors have read and agreed to the published version of the manuscript.

Funding: This work was supported by National Key R\&D Program of China (2018YFD0201202, 2017YFD0201108), Zhejiang National Natural Science Foundation of China (LY17C010006), The AgriX Interdisciplinary Fund of Shanghai Jiao Tong University (Agri-X2017010), State Key Laboratory for Biology of Plant Diseases and Insect Pests (SKLOF201802), the Open Project Program of State Key Laboratory of Rice Biology (20190109) and Shanghai Committee of Science and Technology (19390743300).

Institutional Review Board Statement: Not applicable.

Informed Consent Statement: Not applicable.

Data Availability Statement: All data supporting the conclusions of this article are included in this article and its additional files. The complete genome sequences have been deposited at DDBJ/EMBL/GenBank and the bioproject ID is PRJNA160245. 
Acknowledgments: We thank John LiPuma at Michigan Medicine Ped Infectious Disease. C. S. Mott Children's Hospital for providing the AU6208 strain to us.

Conflicts of Interest: The authors declare that they have no competing interests.

\section{References}

1. Ashburner, M.; Ball, C.A.; Blake, J.A.; Botstein, D.; Butler, H.; Cherry, J.M.; Davis, A.P.; Dolinski, K.; Dwight, S.S.; Eppig, J.T.; et al. Gene ontology: Tool for the unification of biology. Nat. Genet. 2000, 25, 25-29. [CrossRef] [PubMed]

2. Bernier, S.P.; Sokol, P.A. Use of suppression-subtractive hybridization to identify genes in the Burkholderia cepacia complex that are unique to Burkholderia cenocepacia. J. Bacteriol. 2005, 187, 5278-5291. [CrossRef]

3. Beverley, S.M.; Owens, K.L.; Showalter, M.; Griffith, C.L.; Doering, T.L.; Jones, V.C.; McNeil, M.R. Eukaryotic UDPGalactopyranose Mutase (GLF Gene) in microbial and metazoal pathogens. Eukaryot. Cell 2005, 4, 1147-1154. [CrossRef]

4. Bhatt, G.; Denny, T.P. Ralstonia solanacearum iron scavenging by the siderophore Staphyloferrin B is controlled by PhcA, the global virulence regulator. J. Bacteriol. 2004, 186, 7896-7904. [CrossRef] [PubMed]

5. Capella-Gutiérrez, S.; Silla-Martínez, J.M.; Gabaldón, T. trimAl: A tool for automated alignment trimming in large-scale phylogenetic analyses. Bioinformatics 2009, 25, 1972-1973. [CrossRef] [PubMed]

6. Caruso, G.; Cavaliere, C.; Foglia, P.; Gubbiotti, R.; Samperi, R.; Laganà, A. Analysis of drought responsive proteins in wheat (Triticum durum) by 2D-PAGE and MALDI-TOF mass spectrometry. Plant. Sci. 2009, 177, 570-576. [CrossRef]

7. Chen, L.; Yang, J.; Yu, J.; Yao, Z.; Sun, L.; Shen, Y.; Jin, Q. VFDB: A reference database for bacterial virulence factors. Nucleic Acids Res. 2005, 33, D325-D328. [CrossRef]

8. Cheung, J.; Beasley, F.C.; Liu, S.; Lajoie, G.A.; Heinrichs, D.E. Molecular characterization of staphyloferrin B bio-synthesis in Staphylococcus aureus. Mol. Microbiol. 2009, 74, 594-608. [CrossRef]

9. Coenye, T.; Peeters, E.; Nelis, H.J. Biofilm formation by Propionibacterium acnes is associated with increased resistance to antimicrobial agents and increased production of putative virulence factors. Res. Microbiol. 2007, 158, 386-392. [CrossRef]

10. Dale, S.E.; Doherty-Kirby, A.; Lajoie, G.; Heinrichs, D.E. Role of siderophore biosynthesis in virulence of Staphylo-coccus aureus: Identification and characterization of genes involved in production of a siderophore. Infect. Immun. 2004, 72, 29-37. [CrossRef]

11. DeFeyter, R.; Kado, C.I.; Gabriel, D.W. Small, stable shuttle vectors for use in Xanthomonas. Gene 1990, 88, 65-72. [CrossRef]

12. Devescovi, G.; Bigirimana, J.; Degrassi, G.; Cabrio, L.; Lipuma, J.J.; Kim, J.; Hwang, I.; Venturi, V. Involvement of a quorumsensing-regulated lipase secreted by a clinical isolate of Burkholderia glumae in severe disease symptoms in rice. Appl. Environ. Microbiol. 2007, 73, 4950-4958. [CrossRef] [PubMed]

13. Francis, F.; Kim, J.; Ramaraj, T.; Farmer, A.; Rush, M.C.; Ham, J.H. Comparative genomic analysis of two Burkholderia glumae strains from different geographic origins reveals a high degree of plasticity in genome structure associated with genomic islands. Mol. Genet. Genom. 2013, 288, 195-203. [CrossRef] [PubMed]

14. Goo, E.; Kang, Y.; Kim, H.; Hwang, I. Proteomic analysis of quorum sensing-dependent proteins in Burkholderia glumae. J. Proteome Res. 2010, 9, 3184-3199. [CrossRef] [PubMed]

15. Goo, E.; Kang, Y.; Lim, J.Y.; Ham, H.; Hwang, I. Lethal consequences of overcoming metabolic restrictions imposed on a cooperative bacterial population. mBio 2017, 8, e00042-17. [CrossRef]

16. Guo, W.; Cai, L.-L.; Zou, H.-S.; Ma, W.-X.; Liu, X.-L.; Zou, L.-F.; Li, Y.-R.; Chen, X.-B.; Chen, G.-Y. Ketoglutarate transport protein $\mathrm{KgtP}$ is secreted through the type III secretion system and contributes to virulence in Xanthomonas oryzae pv. oryzae. Appl. Environ. Microbiol. 2012, 78, 5672-5681. [CrossRef]

17. Ham, J.H.; Melanson, R.A.; Rush, M.C. Burkholderia glumae: Next major pathogen of rice? Mol. Plant. Pathol. 2011, 12, 329-339. [CrossRef]

18. Hao, L.-Y.; Willis, D.K.; Andrews-Polymenis, H.; McClelland, M.; Barak, J.D. Requirement of siderophore biosyn-thesis for plant colonization by Salmonella enterica. Appl. Environ. Microbiol. 2012, 78, 4561-4570. [CrossRef]

19. Ichikawa, N.; Sasagawa, M.; Yamamoto, M.; Komaki, H.; Yoshida, Y.; Yamazaki, S.; Fujita, N. DoBISCUIT: A database of secondary metabolite biosynthetic gene clusters. Nucleic Acids Res. 2013, 41, D408-D414. [CrossRef]

20. Jeong, Y.; Kim, J.; Kim, S.; Kang, Y.; Nagamatsu, T.; Hwang, I. Toxoflavin produced by Burkholderia glumae causing rice grain rot is responsible for inducing bacterial wilt in many field crops. Plant. Dis. 2003, 87, 890-895. [CrossRef]

21. Jia, B.; Raphenya, A.R.; Alcock, B.; Waglechner, N.; Guo, P.; Tsang, K.K.; Lago, B.A.; Dave, B.M.; Pereira, S.; Sharma, A.N.; et al. CARD 2017: Expansion and model-centric curation of the comprehensive antibiotic resistance database. Nucleic Acids Res. 2016, 45, D566-D573. [CrossRef] [PubMed]

22. Katoh, K.; Standley, D.M. MAFFT multiple sequence alignment software version 7: Improvements in performance and usability. Mol. Biol. Evol. 2013, 30, 772-780. [CrossRef]

23. Kim, J.-W.; Kang, Y.-S.; Kim, J.-G.; Choi, O.-H.; Hwang, I.-G. Occurrence of Burkholderia glumae on rice and field crops in Korea. Plant. Pathol. J. 2010, 26, 271-272. [CrossRef]

24. Kim, S.; Cho, Y.-J.; Song, E.-S.; Lee, S.H.; Kim, J.-G.; Kang, L.-W. Time-resolved pathogenic gene expression analysis of the plant pathogen Xanthomonas oryzae pv. oryzae. BMC Genom. 2016, 17, 345. [CrossRef] [PubMed]

25. Tanner, J.J.; Sobrado, P. Targeting UDP-Galactopyranose mutases from eukaryotic human pathogens. Curr. Pharm. Des. 2013, 19, 2561-2573. [CrossRef] 
26. Krogh, A.; Larsson, B.; Von Heijne, G.; Sonnhammer, E.L. Predicting transmembrane protein topology with a hidden markov model: Application to complete genomes. J. Mol. Biol. 2001, 305, 567-580. [CrossRef] [PubMed]

27. Kurtz, S.; Phillippy, A.M.; Delcher, A.L.; Smoot, M.; Shumway, M.; Antonescu, C.; Salzberg, S.L. Versatile and open software for comparing large genomes. Genome Biol. 2004, 5, R12. [CrossRef] [PubMed]

28. Lee, H.-H.; Park, J.; Kim, J.; Park, I.; Seo, Y.-S. Understanding the direction of evolution in Burkholderia glumae through comparative genomics. Curr. Genet. 2016, 62, 115-123. [CrossRef]

29. Liu, H.; Yang, C.L.; Ge, M.Y.; Ibrahim, M.; Li, B.; Zhao, W.J.; Chen, G.Y.; Zhu, B.; Xie, G.L. Regulatory role of tetR gene in a novel gene cluster of Acidovorax avenae subsp. avenae RS-1 under oxidative stress. Front. Microbiol. 2014, 5, 547. [CrossRef]

30. Mondal, K.K.; Mani, C.; Verma, G. Emergence of bacterial panicle blight caused by Burkholderia glumae in North India. Plant. Dis. 2015, 99, 1268. [CrossRef]

31. Nandakumar, R.; Rush, M.; Shahjahan, A.; O'Reilly, K.; Groth, D. Bacterial panicle blight of rice in the southern United States caused by Burkholderia glumae and B-gladioli. Phytopathology 2005, 95, S73.

32. Nandakumar, R.; Rush, M.C.; Correa, F. Association of Burkholderia glumae and B. gladioli with panicle blight symptoms on rice in panama. Plant. Dis. 2007, 91, 767. [CrossRef] [PubMed]

33. Nandakumar, R.; Shahjahan, A.K.M.; Yuan, X.L.; Dickstein, E.R.; Groth, D.; Clark, C.A.; Cartwright, R.D.; Rush, M.C. Burkholderia glumae and B. gladioli cause bacterial panicle blight in rice in the Southern United States. Plant. Dis. 2009, 93, 896-905. [CrossRef] [PubMed]

34. Nguyen, M.; Ekstrom, A.; Li, X.; Yin, Y. HGT-Finder: A new tool for horizontal gene transfer finding and application to aspergillus genomes. Toxins 2015, 7, 4035-4053. [CrossRef] [PubMed]

35. Nogueira, T.; Rankin, D.J.; Touchon, M.; Taddei, F.; Brown, S.P.; Rocha, E.P. Horizontal gene transfer of the se-cretome drives the evolution of bacterial cooperation and virulence. Curr. Biol. 2009, 19, 1683-1691. [CrossRef]

36. Overbeek, R.; Olson, R.; Pusch, G.D.; Olsen, G.J.; Davis, J.J.; Disz, T.; Edwards, R.A.; Gerdes, S.; Parrello, B.; Shukla, M.; et al. The SEED and the Rapid Annotation of microbial genomes using Subsystems Technology (RAST). Nucleic Acids Res. 2014, 42, D206-D214. [CrossRef]

37. Patel, A.K.; Laroche, C.; Marcati, A.; Ursu, A.V.; Jubeau, S.; Marchal, L.; Petit, E.; Djelveh, G.; Michaud, P. Separation and fractionation of exopolysaccharides from Porphyridium cruentum. Bioresour. Technol. 2013, 145, 345-350. [CrossRef]

38. Petersen, T.N.; Brunak, S.; Von Heijne, G.; Nielsen, H. SignalP 4.0: Discriminating signal peptides from trans-membrane regions. Nat. Methods 2011, 8, 785-786. [CrossRef]

39. Pruitt, K.D.; Tatusova, T.; Maglott, D.R. NCBI reference sequences (RefSeq): A curated non-redundant sequence database of genomes, transcripts and proteins. Nucleic Acids Res. 2006, 35, D61-D65. [CrossRef]

40. Quevillon, E.; Silventoinen, V.; Pillai, S.; Harte, N.; Mulder, N.; Apweiler, R.; Lopez, R. InterProScan: Protein do-mains identifier. Nucleic Acids Res. 2005, 33, W116-W120. [CrossRef]

41. Riera-Ruiz, C.; Vargas, J.; Cedeño, C.; Quirola, P.; Escobar, M.; Cevallos-Cevallos, J.M.; Ratti, M.; Peralta, E.L. First report of Burkholderia glumae causing bacterial panicle blight on rice in Ecuador. Plant. Dis. 2014, 98, 988. [CrossRef] [PubMed]

42. Salloum, T.; Nassour, E.; Araj, G.F.; Abboud, E.; Tokajian, S. Insights into the genome diversity and virulence of two clinical isolates of Burkholderia cenocepacia. J. Med. Microbiol. 2018, 67, 1157-1167. [CrossRef] [PubMed]

43. Seo, Y.-S.; Lim, J.Y.; Park, J.; Kim, S.; Lee, H.-H.; Cheong, H.; Kim, S.-M.; Moon, J.S.; Hwang, I. Comparative genome analysis of rice-pathogenic Burkholderia provides insight into capacity to adapt to different environments and hosts. BMC Genom. 2015, 16, 1-11. [CrossRef] [PubMed]

44. Turner, K.H.; Wessel, A.K.; Palmer, G.C.; Murray, J.L.; Whiteley, M. Essential genome of Pseudomonas aeruginosa in cystic fibrosis sputum. Proc. Natl. Acad. Sci. USA 2015, 112, 4110-4115. [CrossRef]

45. Untergasser, A.; Cutcutache, I.; Koressaar, T.; Ye, J.; Faircloth, B.C.; Remm, M.; Rozen, S.G. Primer3-New capabilities and interfaces. Nucleic Acids Res. 2012, 40, e115. [CrossRef]

46. Valade, E.; Thibault, F.; Gauthier, Y.; Palencia, M.; Popoff, M.; Vidal, D. The PmlI-PmlR quorum-sensing system in Burkholderia pseudomallei plays a key role in virulence and modulates production of the MprA protease. J. Bacteriol. 2004, 186, $2288-2294$. [CrossRef]

47. Varghese, N.J.; Mukherjee, S.; Ivanova, N.; Konstantinidis, K.T.; Mavrommatis, K.; Kyrpides, N.C.; Pati, A. Microbial species delineation using whole genome sequences. Nucleic Acids Res. 2015, 43, 6761-6771. [CrossRef]

48. Weinberg, J.B.; Alexander, B.D.; Majure, J.M.; Williams, L.W.; Kim, J.Y.; Vandamme, P.; Lipuma, J.J. Burkholderia glumae infection in an infant with chronic granulomatous disease. J. Clin. Microbiol. 2007, 45, 662-665. [CrossRef] 
49. Zhou, X.G. First report of bacterial panicle blight of rice caused by Burkholderia glumae in South Africa. Plant. Dis. 2014, 98, 566. [CrossRef]

50. Zhu, B.; Lou, M.-M.; Xie, G.-L.; Zhang, X.; Zhou, X.; Li, B.; Jin, G. Horizontal gene transfer in silkworm, Bombyx mori. BMC Genom. 2011, 12, 248-249. [CrossRef] 